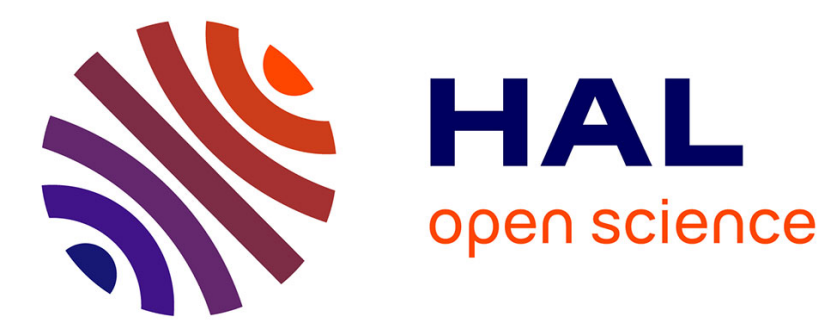

\title{
Non-linear EEG synchronization during observation: Effects of instructions and expertise
}

\author{
Claire Calmels, Magaly Hars, Gilbert Jarry, Cornelis J Stam
}

\section{To cite this version:}

Claire Calmels, Magaly Hars, Gilbert Jarry, Cornelis J Stam. Non-linear EEG synchronization during observation: Effects of instructions and expertise. Psychophysiology, 2010, 47 (5), pp.799-808. 10.1111/j.1469-8986.2010.00985.x . hal-01575609

\section{HAL Id: hal-01575609 https: / hal-insep.archives-ouvertes.fr/hal-01575609}

Submitted on 22 Aug 2017

HAL is a multi-disciplinary open access archive for the deposit and dissemination of scientific research documents, whether they are published or not. The documents may come from teaching and research institutions in France or abroad, or from public or private research centers.
L'archive ouverte pluridisciplinaire HAL, est destinée au dépôt et à la diffusion de documents scientifiques de niveau recherche, publiés ou non, émanant des établissements d'enseignement et de recherche français ou étrangers, des laboratoires publics ou privés. 


\title{
Non-linear EEG synchronization during observation: Effects of instructions and expertise
}

CLAIRE CALMELS, ${ }^{\mathrm{a}}$ MAGALY HARS,,${ }^{\mathrm{a} b}$ GILBERT JARRY,${ }^{\mathrm{c}}$ and CORNELIS J. STAM ${ }^{\mathrm{d}}$

${ }^{a}$ Mission Recherche, Institut National du Sport et de l'É ducation Physique, Paris, France

${ }^{b}$ Ecole doctorale ED 462, Université de Reims Champagne-Ardenne, Reims, France

${ }^{c}$ EA 4391, Université Paris XII, Hô pital Henri Mondor, Cré teil, France

${ }^{\mathrm{d} D e p a r t m e n t ~ o f ~ C l i n i c a l ~ N e u r o p h y s i o l o g y, ~ V U ~ U n i v e r s i t y ~ M e d i c a l ~ C e n t r e, ~ A m s t e r d a m, ~ T h e ~ N e t h e r l a n d s ~}$

\begin{abstract}
The aim of this study was to examine the effects of instructions and expertise upon neuronal changes during observation of sequential finger movements. Professional pianists and musically nai" ve subjects observed these movements with the aim of either replicating or recognizing them at a later stage. A non-linear measure of functional coupling was used to investigate EEG activity. In the $10-13 \mathrm{~Hz}$ frequency band and in musically nai"ve subjects, functional coupling during observation for replica was greater within central and neighboring areas than during observation for recognition. An opposite pattern was found in the $4-8 \mathrm{~Hz}$ frequency band. In the $10-13 \mathrm{~Hz}$ band and in areas including the parietal cortex, functional coupling in musically nai" ve subjects was greater compared to professional pianists under observation for replica. Results are discussed in the light of recent findings from the cognitive and behavioral neuroscience literature.
\end{abstract}

Descriptors: Observation, Synchronization, Instructions, Expertise, Motor skills, Musicians, Electroencephalography

Over the last decade, a large number of studies in the field of neuroscience have been conducted on observation and imitation (e.g., Calvo-Merino, Glaser, Grezes, Passingham, \& Haggard, 2005; Calvo-Merino, Grezes, Glaser, Passingham, \& Haggard, 2006; Decety, Grezes, Costes, Perani, Jeannerod, et al., 1997; Grezes, Costes, \& Decety, 1998; Haslinger, Erhard, Altenmuller, Schroeder, Boecker, \& Ceballos-Baumann, 2005; Iacoboni, Woods, Brass, Bekkering, Mazziotta, \& Rizzolatti, 1999; Makuuchi, 2005; Muthukumaraswamy, Johnson, \& McNair, 2004; Zentgraf, Stark, Reiser, Kunzell, Schienle, et al., 2005). However, with the exception of the studies undertaken by Decety et al. (1997), Grezes et al. (1998), Suchan, Melde, Herzog, Homberg, and Seitz (2008), and Zentgraf et al. (2005), the influence of the nature of instructions provided prior to observation of biological movements on brain activity has not been examined extensively. Decety et al. (1997) and Grezes et al. (1998) were the first researchers to take into account this factor. Using positron emission tomography (PET), they investigated the neural network involved when subjects were invited to observe an action with the purpose of: (i) later imitation; (ii) later recognition; or (iii) to observe the movement with no specific goal. They also manip-

This study was supported by a grant from the French Ministry of Health, Youth, and Sports. The authors are grateful to the participants who participated in the study. They would also like to thank M. Paisley for the video footage editing.

Address reprint requests to: Claire Calmels, Mission Recherche, Institut National du Sport et de l'Education Physique, 11 Avenue du Tremblay, 75012 Paris, France. E-mail: claire.calmels@insep.fr ulated the semantic content of the action: it was either a meaningful action (i.e., familiar to the individual; e.g., pantomimes of transitive acts) or a meaningless action (i.e., unknown to the individual; e.g., actions emanating from the American Sign Language). They found that the instructional sets and the meaning of the actions led to changes in the observational neuronal profile. More specifically, Grezes et al. (1998) have shown that observing meaningful and meaningless actions with no specific instruction activated a common network of areas and specific areas. The left inferior frontal gyrus and the left fusiform gyrus were activated in meaningful actions and the dorsal pathway and the right cerebellum in meaningless actions. Zentgraf et al. (2005) used functional magnetic resonance imagery (fMRI) to observe movements involving the entire body under different instructions: observation for imitation and observation for evaluation. The results demonstrated distinctive activations within the supplementary motor area (SMA). Under an "imitative observation mode," the SMA proper was highly activated, whereas under an "'evaluative observation mode," the pre-SMA was more strongly activated. Very recently, Suchan et al. (2008), with PET, have found activation differences whilst individuals observed hand movement for imitation or evaluation. The dorsal pathway was involved during observation for imitation whereas the ventral pathway was at play during observation for velocity judgment.

A limited amount of research investigating the neural bases of the observation process has considered expertise as a variable (Babiloni, Del Percio, Rossini, Marzano, Iacoboni, et al., 2009; Calvo-Merino et al., 2005, 2006; Haslinger et al., 2005). Experts 
are defined as individuals who exhibit a high level of performance in a particular domain, which has been acquired through a long and high commitment (Ericsson, Krampe, \& Tesch-Romer, 1993). Calvo-Merino et al. (2006) have shown that the activation of the premotor, parietal cortices, and cerebellum was a result of the motor competence of the observer and was closely associated with visual and motor familiarity of the action. More specifically, these authors have studied male and female expert classical dancers who possessed a similar visual familiarity of the ballet moves but not a motor familiarity since some of the ballet moves are specific to one sex and had, therefore, not been physically trained by the other gender group. Greater parietal, premotor, and cerebellar activations were found for observation of genderspecific ballet moves in contrast to visually familiar, but untrained, ballet moves. Haslinger et al. (2005) found similar results to those of Calvo-Merino et al. (2006) in the field of music and with the use of fMRI. They investigated cortical activations in expert pianists who had practiced the piano for 17 years and in neophyte subjects in music. They found greater activations within a fronto-parieto-temporal circuitry in professional pianists than in inexperienced pianists when passively viewing soundless piano playing movements using the right hand contrasted to the observation of a resting hand or sequential fingerto-thumb opposition movements. Very recently, Babiloni et al. (2009), with the use of electroencephalography (EEG), examined the cortical activation when elite rhythmic gymnasts and nongymnasts watched gymnastic sequences in order to subsequently judge the observed routines. They revealed a higher cortical activation in alpha frequency bands in non-gymnasts within the ventral and dorsal pathways.

To our knowledge, no studies have manipulated simultaneously the two aforementioned variables (i.e., nature of instructions and level of expertise) when investigating neural processes of observation. Addressing the effects of these two variables in a single experiment would allow examining the influence of the observer intentions (instruction) and the influence of a long-term practice (expertise) upon the cortical observation network. More specifically, when experts and non-experts observe an action in order to replicate it or to recognize it at a later stage, examining the cerebral rhythmic activities may be worthwhile since it allows gaining knowledge about the mechanisms of action observation. Therefore, this was the aim of the present study.

Experts were selected among a population of professional pianists. This specific population was chosen for two reasons. First, pianists are considered to be experts in manual dexterity, which has been acquired through their daily musical training. They could thus be easily compared with musically nai" ve subjects who did not have any experience in playing musical instruments. Second, movement of the fingers is a task that is perfectly ap- propriate to the constraints of EEG since it allows data collection during the execution stage of a movement. Since finger move- ments are performed at a distance from the scalp, no movement artifacts in the EEG are expected (Derambure, Defebvre, Bourriez, Cassim, \& Guieu, 1999).

The investigation of cerebral rhythmic activities has been completed with the synchronization likelihood (SL) measure, which is a marker of linear and non-linear changes in functional coupling between different brain areas (Montez, LinkenkaerHansen, van Dijk, \& Stam, 2006; Stam \& van Dijk, 2002). Central and neighboring cortical areas were considered since these are known to be involved during action observation (Pineda,
2005; Rizzolatti, Craighero, \& Fadiga, 2002). First, the central zone, which comprises the sensorimotor cortex, is recognized as being activated during observation of actions performed by conspecifics (Lepage \& Thé oret, 2006; Muthukumaraswamy et al., 2004; Pineda, 2005). This activity is reflected by a suppression or a modulation of the mu rhythm, an $8-13 \mathrm{~Hz}$ rhythm generated in the sensorimotor cortex. Besides, the supplementary motor area, which is part of the mesial frontal cortex, is known to be the hand representation area (Chainay, Krainik, Tanguy, Gerardin, Le Bihan, \& Lehé ricy, 2004). Second, frontal and parietal areas are recognized as being interdependently connected to allow trans- formation of sensory information into actions (Matelli \& Lup- pino, 2000; Rizzolatti, Luppino, \& Matelli, 1998). These areas are also activated when humans observe actions performed by the hands or arms (Rizzolatti \& Craighero, 2004; Rizzolatti et al., 2002). Finally, the parietal cortex seems to play a major role in action representation (Bonda, Petrides, Ostry, \& Evans, 1996; Iacoboni et al., 1999; Sirigu, Duhamel, Cohen, Pillon, Dubois, \& Agid, 1996). For example, Sirigu et al. (1996) suggested that this area was of prime importance to store or/and access motor representations. In the same vein, Iacoboni et al. (1999) suggested that a kinesthetic representation of an observed movement was generated in the right parietal lobe when viewing this movement.

It was hypothesized that, in musically nai" ve subjects, inter- regional functional coupling during action observation with the purpose of replicating the action would be greater than during action observation with the aim of recognizing the action. Under the former observation condition, transformation of visual in- formation into motor codes (Jeannerod, Arbib, Rizzolatti, \& Sakata, 1995), argued to require additional population of neu- rons, would generate greater cognitive demands compared to those identified under observation with the aim of recognition, in which such transformation is unnecessary (Zentgraf et al., 2005). It was also expected that, in professional pianists, inter-regional functional coupling would not display significant differences be- tween the two observation conditions, since musicians who are extremely well educated in processing visuomotor transforma- tion (Palmer, 1997) do not need to recruit extra neuronal network under observation for replica. This last point has been supported by the idea that a great level of expertise is related to a reduced processing treatment (e.g., Haslinger, Erhard, Altenmuller, Hennenlotter, Schwaiger, et al., 2004; Jancke, Shah, \& Peters, 2000; Koeneke, Lutz, Wustenberg, \& Jancke, 2004; Krings, Topper, Foltys, Erberich, Sparing, et al., 2000, Meister, Krings, Foltys, Boroojerdi, Muller, et al., 2005). As a consequence of these two hypotheses, it was predicted that observation for replica among musically nai ve subjects would elicit greater functional coupling than observation for replica among profes- sional pianists. Modifications in functional coupling would be mainly conjectured to occur in theta band $(4-8 \mathrm{~Hz})$ and in alpha bands $(8-13 \mathrm{~Hz})$, since oscillations in these two bands play an important role during the encoding of information (Klimesch, 1999; Sauseng, Klimesch, Gruber, Doppelmayr, Stadler, \& Schabus, 2002; Sauseng, Klimesch, Schabus, \& Doppelmayr, 2005). Moreover, reverse patterns of coupling would be observed between theta and alpha bands. It is well recognized in the sci- entific literature that, during analyses of mental activity, EEG alpha activity desynchronizes in terms of power decrease, whereas EEG theta activity synchronizes in terms of power in- crease (Klimesch, 1996, 1999; Klimesch, Doppelmayr, Schimke, \& Ripper, 1997a). 
Experimental Methods

\section{Subjects}

Eleven right-handed professional pianists (eight men and three women; mean age 526.63 , SD 54.99 ) and twelve right-handed musically naive subjects (eight males and four females; mean age 5 24.79, SD 53.61) were included in the study. Professional pianists played the piano for at least 10 years and had on average $25 \mathrm{~h}$ of piano practice per week. Musically naive subjects had no experiences in playing a musical instrument. All the subjects were assessed as right-handed by the Edinburgh Handedness Inventory (Oldfield, 1971) and did not report the presence of any neurological or psychiatric disorders. All subjects provided written informed consent and were kept blind to the goals of the study. The study was approved by the local institutional ethics committee.

\section{Task}

The task was a sequential finger movement, which consisted of touching the tip of the right thumb with the tip of the other right hand fingers with the hand in a supine position and resting on a pillow. The movement comprised four finger contacts performed at a rate of $2 \mathrm{~Hz}$. There were 40 different movements with nonrepeated contact performed consecutively (e.g., 1321, 4312, 2423); 1 was the index finger, 2 the middle finger, 3 the ring finger, and 4 the little finger.

\section{Experimental Procedure}

The subjects were examined in three conditions: (i) a movement observation condition aimed at replicating the observed movement; (ii) a movement observation condition aimed at recognizing the observed movement; and (iii) a control condition. Multichannel EEG was recorded whilst participants sat in a darkened room with their forearms lying on armrests in a supine position. To reduce eye movement and other electromyographic artifacts throughout the EEG data collection, subjects were asked to refrain from blinking by maintaining their gaze on a fixation point placed in the middle of the screen situated $1.30 \mathrm{~m}$ in front of them and to keep their jaw relaxed. These instructions were provided before each condition.

\section{Movement Observation Condition for Replica}

Each subject observed 40 movements embedded in 40 trials. Each trial comprised five stages which were shown to the subject via a video display. During the first stage of each trial, lasting $4 \mathrm{~s}$, the subject watched a blue monitor screen. Two seconds after the onset of this stage, the word "perform" appeared on the screen to invite the subject to observe the movement with the goal of replicating it at a later stage. During the second stage lasting $3.24 \mathrm{~s}$, the subject observed a video of a human model performing a finger movement sequence at $2 \mathrm{~Hz}$ from an egocentric perspective. An egocentric perspective (i.e., a first-person perspective) has been chosen, since it is congruent to the visual perspective of the observer, whereas an allocentric perspective (i.e., a third-person perspective) is other centered. Moreover, an egocentric perspective yields more activity, during observation, in the contralateral sensorimotor cortex compared to an allocentric perspective (Jackson, Meltzoff, \& Decety, 2006). This result is consistent with the findings of Maeda, Kleiner-Fisman, and Pascual-Leone (2002). Maeda et al. (2002) have shown a greater motor corticospinal excitability for observed hand actions under an egocentric perspective. In the third stage, lasting $3.76 \mathrm{~s}$, an amber background was presented requiring the subject to stay focused. In the fourth stage lasting $3.24 \mathrm{~s}$, a black screen was displayed and invited the subject to perform the finger movement sequence viewed in the second stage. While the subjects performed the finger movements, the experimenter monitored the accuracy of the movements. Incorrect sequences of finger taps were discarded from subsequent analysis. In the fifth stage lasting $6 \mathrm{~s}$, the screen changed to red and the subject was encouraged to relax, to think of nothing, and to blink her/his eyes if necessary (see Figure 1). The time interval between the beginning of viewing the movement and the onset of the next was 20.24 s (see Figure 1).

\section{Movement Observation Condition for Recognition}

The 40 trials under this condition were conducted in a similar way to those used in the movement observation condition for reproduction. However, in the first stage, the word "recognize" appeared on the blue screen in order to invite the subject to observe the movement with the goal of recognizing it at a later stage. The fourth stage was also different in that a video was presented to the subject. This video was similar or dissimilar than that viewed in the second stage. Fifty percent of the videos were similar. At the beginning of the fifth stage, the word "answer" appeared for $2 \mathrm{~s}$ on the red screen to prompt the subject to clench her/his fist whether the second video was different from the first video. When the second video was identical to the first one, the subject did nothing. Only correct answers were retained for analysis.

\section{Control Condition}

This condition followed a similar procedure to the observation conditions. However, instead of observing movements during the second and fourth stages, the subject observed a pillow during two periods each lasting $3.24 \mathrm{~s}$ (see Figure 1).

All trials for each of the three conditions were triggered using a specifically designed interface based on a photoresistive diode, which responded to the screen color change. Four 10-min blocks of 30 trials were performed. Each block was separated by a 5-min rest period. The order of the 120 trials was randomized across the four blocks. During all the conditions apart from the fourth stage of the observation condition for replica, the experimenter verified that the subject did not move his/her fingers.

\section{Data Acquisition and Recording}

Electrical brain activity was recorded from 19 electrodes (Fp1, Fp2, Fz, F7, F8, F3, F4, Cz, C3, C4, PZ, P3, P4, T3, T4, T5, T6, $\mathrm{O} 1$, and $\mathrm{O} 2$ ) mounted in an elastic lycra cap (Electro-cap International, Eaton, $\mathrm{OH}$ ) and placed in accordance with the international 10-20 system (Jasper, 1958). Mastoids were used for the reference electrodes, and the ground electrode was located on the forehead. Electro-oculograms (EOG) were also registered from the canthi of both eyes (horizontal EOG) and the supra and infra orbital of the right eye (vertical EOG). Electrode impedance was kept homogenously below $5 \mathrm{kO}$ throughout the experimentation and was checked systematically between the four blocks of trials. Amplifier bandwidth was set between 0.15 and $114 \mathrm{~Hz}$ using a computer-based EEG recorder (Coherence, Deltamed, Paris, France). Baseline-corrected activity was sampled at $256 \mathrm{~Hz}$. AD resolution was 16 bit.

\section{Synchronization Likelihood}

Synchronization Likelihood (SL) is a general measure of linear and non-linear correlations between EEG signals (Stam \& van Dijk, 2002; Montez et al., 2006). This measure characterizes interchannel synchronization and is the likelihood that recurrence of a pattern in time series $\mathrm{X}$ at two times $\mathrm{i}$ and $\mathrm{j}$ will coincide with 


\begin{tabular}{|c|c|c|c|c|c|}
\hline Stages & Stage 1 & $\begin{array}{c}\text { Stage } 2 \\
\text { (Observation) }\end{array}$ & Stage 3 & $\begin{array}{c}\text { Stage } 4 \\
\text { (Execution or } \\
\text { Observation) }\end{array}$ & $\begin{array}{l}\text { Stage } 5 \\
\text { (Rest) }\end{array}$ \\
\hline Stages duration & $4 \mathrm{~s}$ & $3.24 \mathrm{~s}$ & $3.76 \mathrm{~s}$ & $3.24 \mathrm{~s}$ & $6 \mathrm{~s}$ \\
\hline Screen colour & Blue & & Amber & Black & Red \\
\hline $\begin{array}{l}\text { Observation condition } \\
\text { for replica }\end{array}$ & PERFORM & & & & \\
\hline $\begin{array}{l}\text { Observation condition } \\
\text { for recognition }\end{array}$ & RECOGNIZE & & & & RESPONSE \\
\hline Control condition & & & & & \\
\hline
\end{tabular}

Figure 1. Schema for one trial according to condition. The second stage lasted $3.24 \mathrm{~s}$ since two periods of $505 \mathrm{~ms}$ (i.e., $505 \mathrm{~ms}$ before the onset of the movement and $505 \mathrm{~ms}$ after its end) were added to the 2.23-s duration of the movement. During these time lapses, the subject could visualize the hand and fingers at rest. This was done to allow the subject to understand the context in which the movement was performed and to avoid abrupt video image changes.

recurrence of patterns in time series $\mathrm{Y}$ at the same times $\mathrm{i}$ and $\mathrm{j}$. The patterns are defined in terms of state-space vectors obtained by time-delay embedding of the data. The SL takes on values between $p_{\text {ref }}$ (no coupling) and 1 (complete coupling). Pref is a parameter of the computation of synchronization likelihood, and is usually chosen as Pref50.01.

\section{Data Processing}

EEG data were analyzed in five frequency bands: $4-8 \mathrm{~Hz}, 8-10$ $\mathrm{Hz}, 10-13 \mathrm{~Hz}, 13-20 \mathrm{~Hz}$, and $20-30 \mathrm{~Hz}$. The choice of these band widths was based on previous coherence, connectivity research (Andres, Mima, Schulman, Dichgans, Hallett, \& Gerloff, 1999; Calmels, Hars, Holmes, Jarry, \& Stam, 2008; Holz, Doppelmayr, Klimesch, \& Sauseng, 2008; Stam, de Haan, Daffertshofer, Jones, Manshanden, et al., 2009). Data processing was composed of three steps: segmentation of EEG trials; removal of ocular artifacts; and SL computation.

Segmentation of EEG trials. A total of 30 trials were completed during each 10-min block. Each trial was subdivided into five stages. Off-line analysis of the first stage revealed that muscular artifacts contaminated the data in the first second of some trials. Consequently, this stage was reduced to $3 \mathrm{~s}$ in length and the first second was discarded. The fifth stage, during which the subject was prompted to relax, was also removed, since this stage contained numerous ocular and muscular artifacts. Four stages were distinguished within a trial after the off-line analysis: the first stage $(0-3 \mathrm{~s})$, the second stage $(3-6.24 \mathrm{~s})$, the third stage (6.24-10 s), and the fourth stage (10-13.24 s) (see Figure 1). Only the second stage (3-6.24 s) was used for the EEG analysis.

Removal of ocular artifacts. Ocular artifacts were corrected via Semlitsch, Anderer, Schuster, and Presslich's (1986) method. This artifact removal was performed with Neuroscan 4.1 software (Revision A, 1999). The following options were selected: trigger: positive direction, threshold: $20 \%$; blink values: 2 min- imum sweeps, average artifact duration: $400 \mathrm{~ms}$, and VEOG as the channel used in this computation; review: maxima and blinks enabled; and output: LDR1CNT.

SL computation. SL was computed for all the 171 electrode pairs (stemming from 19 electrode sites) for the second stage for each of the trials of the three conditions, for each subject and frequency band. The $171 \mathrm{SL}$ values were averaged across trials for each subject, condition, and frequency band. Parameters for the computation of the synchronization likelihood were: 1 sample for the lag; 8 for the embedding dimension; 8 for the Theiler correction $\left(\mathrm{w}_{1}\right)$; and 0.010 for Pref. These parameter choices were necessary because of the very short duration of the stage to which the SL was implemented (see Appendix 1). To diminish the variability between subjects and electrode pairs, the SL value under the control condition was subtracted from the SL value under the observation condition as stated by the formula: $\mathrm{SL}_{\text {final }} 5$ $\mathrm{SL}_{\text {observation condition }}-\mathrm{SL}_{\text {control condition }}$ (Manganotti, Gerloff, Toro, Katsuda, Sadato, et al., 1998; Gerloff, Richard, Hadley, Schulman, Honda, \& Hallett, 1998). A positive $\mathrm{SL}_{\text {final }}$ value indicated a SLincrease, whereas a negative value represented a SLdecrease.

\section{Statistical Analysis}

All statistical analyses were performed using Statistica software 7. From the electrode montage, F4, F3, C4, C3, P4, P3, FZ, CZ, and $\mathrm{PZ}$ were chosen for analysis because these electrode sites overlie the central and neighboring cortical areas that are known to be involved during action observation (Pineda, 2005; Rizzolatti et al., 2002). These electrode sites also displayed the highest EEG synchronization under the conditions of observation and execution of finger movements (Calmels, Holmes, Jarry, Hars, Lopez, et al., 2006) and revealed EEG patterns during hand/ finger action observation akin to those revealed during hand/ finger action execution (Babiloni, Babiloni, Carducci, Cincotti, Del Percio, et al., 2002; Calmels et al., 2008). 
In the present study, the number of links between the nine electrode sites belonging to the central and neighboring areas (i.e., the zone of interest) was 36 (C4-C3, C4-FZ, C4-CZ, C3-FZ, C3-CZ, FZ-CZ, F4-F3, F4-P4, F4-P3, F4-PZ, F3-P4, F3-P3, F3-PZ, P4-P3, P4-PZ, P3-PZ, F4-C4, F4-C3, F4-FZ, F4-CZ, F3-C4, F3-C3, F3-FZ, F3-CZ, C4-P4, C4-P3, C4-PZ, C3-P4, C3-P3, C3-PZ, P4-FZ, P4-CZ, P3-FZ, P3-CZ, FZ-PZ, CZ-PZ) (see Figure 2). For each of the five frequency bands and subjects, we averaged the $36 \mathrm{SL}$ values within the central and neighboring areas to obtain one overall SL value.

Two (conditions) $\times 2$ (groups) multivariate analysis of variance (MANOVAs) were completed for each of the frequency bands. There was one within-subject factor; condition (two levels: observation for replica, observation for recognition) and one between-subject factor; group (two levels: musically nai" ve sub- jects, professional pianists). Post hoc comparisons were calcu- lating using Fisher's LSD test where MANOVA results were significant. Before the MANOVA computations, the normality of the data was checked with the KolmogorovSmirnov test.

Results

\section{Behavioral Results}

During observation for replica, the percentages of correct finger taps performed by the musically nai" ve subjects and the profes- sional pianists were, respectively, $84 \%$ and $96.8 \%$. This differ- ence was statistically significant (Mann-Whitney, U 515.50 ,

po.002). During observation for recognition, the percentages were $91 \%$ for the musically nai" ve subjects and $99.3 \%$ for the

professional pianists. This difference was statistically significant (Mann-Whitney, U 5 15.50, po.002). Percentages of correct finger taps between the observation for replica and the observation for recognition were statistically different in musically nai ve

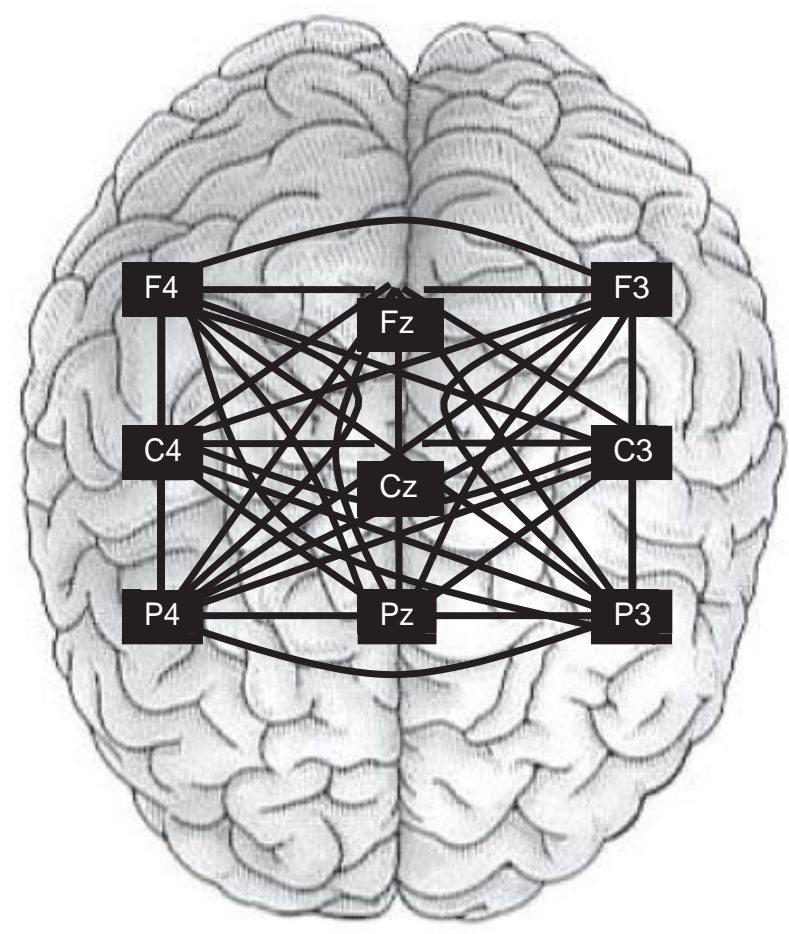

Figure 2. Connections between electrode sites within the central and neighboring areas.
Table 1. Summary of the 2 (Conditions) $\times 2$ (Groups) MANOVAsforEach FrequencyBand

\begin{tabular}{|c|c|c|c|c|c|c|c|c|c|c|}
\hline \multirow[b]{2}{*}{ Interactions } & \multicolumn{2}{|c|}{ 4-8 Hz} & \multicolumn{2}{|c|}{$\begin{array}{c}8-10 \\
\mathrm{~Hz}\end{array}$} & \multicolumn{2}{|c|}{$\begin{array}{c}10-13 \\
\mathrm{~Hz}\end{array}$} & \multicolumn{2}{|c|}{$\begin{array}{c}13-20 \\
\mathrm{~Hz}\end{array}$} & \multicolumn{2}{|c|}{$\begin{array}{c}20-30 \\
\mathrm{~Hz}\end{array}$} \\
\hline & $F$ & $p$ & $F$ & $P$ & $F$ & $p$ & $F$ & $p$ & $F$ & $p$ \\
\hline
\end{tabular}

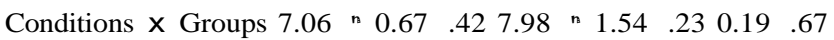

Note: ${ }^{\mathrm{n}} \mathrm{p} 0.015$

subjects (Wilcoxon, T5 .00, po.004) and in professional pianists (Wilcoxon, T53,po.04).

\section{Synchronization Likelihood}

The EEG data were normally distributed. Only results for conditions by groups are reported since they were directly linked to the goals of the present study (see Table 1).

Five 2 (conditions) $\times 2$ (groups) MANOVAs were computed. Significant conditions $\times$ groups interactions were found in the observation stage for: (1) the $4-8 \mathrm{~Hz}$ band, $F(1,21) 57.06$, po.015; (2) the 10-13 Hz band, $F(1,21) 57.98$, po.015 (see Table 1). Fisher's LSD posthoc test analyses were computed and three results were found.

First, Fisher's LSD post hoc test analysis revealed significant differences among musically nar ve subjects between the obser- vation condition for replica and the observation condition for recognition in the $4-8 \mathrm{~Hz}$ frequency band. In this band, under the condition for replica, a weak $\mathrm{SL}_{\text {final }}$ decrease was developed, whereas under the condition for recognition a $\mathrm{SL}_{\text {final }}$ increase was produced (see Figure 3 ).

Second, Fisher's LSD post hoc test analysis also identified a significant difference among musically nai" ve subjects between the observation condition for replica and the observation condition for recognition in the $10-13 \mathrm{~Hz}$ frequency band. $\mathrm{SL}_{\text {final }}$ increase was greater in the observation condition for replica compared to the observation condition for recognition.

Finally, post hoc test analysis also yielded a significant difference, under the observation condition for replica, between musically nai" ve subjects and professional pianists for the $10-13 \mathrm{~Hz}$ frequency band (i.e., a $\mathrm{SL}_{\text {final }}$ increase for the musically nai" ve subjects and a $\mathrm{SL}_{\text {final }}$ decrease for the professional pianists) (see Figure 3).

\section{Discussion}

Observation for Replica and Recognition Among Musically Naï̌e Subjects

Consistent with our first prediction, significant differences in $\mathrm{SL}_{\text {final }}$ across the observation conditions for replica and recognition were observed among musically nai ve subjects in the zone of interest for the theta and upper alpha $(10-13 \mathrm{~Hz})$ frequency bands.

The presence of these differences in theta and upper alpha bands is not a surprising result. It is recognized that theta and alpha rhythms are related to memory process. More specifically, theta oscillations facilitate long-term synaptic potentiation, which is a cellular mechanism involved in memory encoding process (Bliss \& Collingridge, 1993). The present result is in line with the findings of Klimesch and co-workers, which showed that theta power is found to be closely associated to the encoding of new information in episodic short-term memory, whereas upper alpha rhythm is of great importance for long-term memory in retrieval processes. The authors also highlighted that a particular interaction between these two frequency bands is indicative of a transfer 
Electrode connections

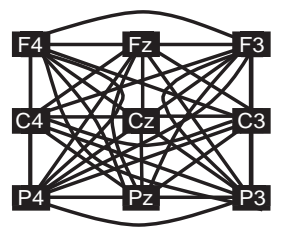

$4-8 \mathrm{~Hz}$

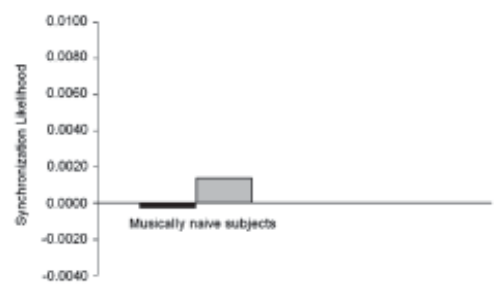

$10-13 \mathrm{~Hz}$

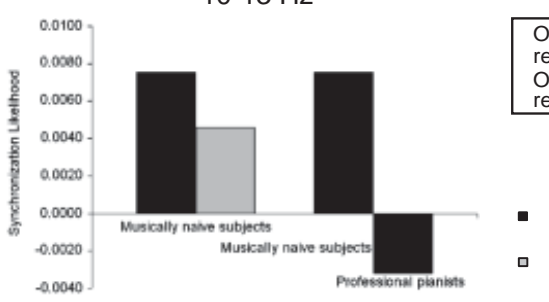

Figure 3. Significant results from the Fisher's LSD post hoc test where conditions $x$ groups interactions were significant. Schema in the left indicates the electrode connections within the area of interest. Charts display the significant differences between musically naï ve subjects and professional pianists under the two observation conditions and for the $4-8 \mathrm{~Hz}$ and $10-13 \mathrm{~Hz}$ frequency bands.

of information between the working and the long-term memories (Sauseng et al., 2002). In the present case, the results obtained in theta and alpha frequency bands are a consequence of the experimental paradigm that has been employed. This paradigm resembles traditional memory paradigms. Data employed for the EEG analysis stem from the observation stage, which is, in fact, an encoding stage. Individuals encode information to store it temporarily in the working memory before performing a recognition task or reproduction task after a delay of a few seconds. The process of encoding also implies that the individuals retrieve from long-term memory the information that will allow them to identify the perceived event before its storage in the working memory (Magill, 2004; Shiffrin \& Geisler, 1973).

The present differences detected between observation for replica and observation for recognition corroborated the findings of Decety et al. (1997) and Zentgraf et al. (2005), who found different neuronal profiles according to the instructions provided to the individuals. For instance, Decety et al. (1997) found activation of the right parahippocampal gyrus, while subjects observed an action in order to recognize it, and this irrespective of the meaning of the action. While subjects observed an action in order to repeat it at a later stage, the dorsolateral prefrontal cortex in both hemispheres, the left pre-supplementary motor area, the left middle occipital gyrus, precuneus, and the right cuneus were activated. Results from a more recent investigation by Zentgraf et al. (2005) showed different kinds of activation within the SMA during gymnastics movement observation tasks where instructions differed. However, comparison with Zentgraf et al.'s (2005) work should be made cautiously, since they invited the subjects, after the observation stage, to mentally simulate the movement from a first-person perspective under the "imitative observation mode." Although mentally performing an action can be perceived as an extremely close motor-related task (Decety \& Grezes, 1999; Grafton, Arbib, Fadiga, \& Rizzolatti, 1996; Grezes \& Decety, 2001; Jeannerod, 2001), nobody, at the present time, is in a position to confirm that observing an action with the aim of replicating it generates cortical phenomena similar to those elicited during the observation of an action with the aim of imagining it. A direct examination of this point would certainly warrant further investigation.

The analysis of the $10-13 \mathrm{~Hz}$ frequency band showed that the $\mathrm{SL}_{\text {final }}$ increase was greater under the observation condition for replica than under the observation condition for recognition in musically nar" ve subjects. This expected finding may be explained by two different mechanisms: a visuomotor transformation (Jeannerod et al., 1995; Zentgraf et al., 2005) and a spatial transformation (Anquetil \& Jeannerod, 2007). First, the visuo- motor transformation, similar to that requested for reaching and grasping objects (Jeannerod et al., 1995; Stark \& Zohary, 2008), was at play in the observation condition for replica. Neurophysiological mechanisms transform perceptual information stemming from the observation of an action performed by others into motor outputs used to guide the execution of the action. Zentgraf et al. (2005) suggested that these mechanisms are not necessary as an individual observes an action with the purpose of recognizing it at a later stage, since under this (observation) condition, no subsequent execution is required. The recognition of an action can be viewed as a distant facet of motor performance, observing an action for recognition is thus treated as a visual event (Jeannerod, 2006) and elicits activation in memory encoding structures such as the parahippocampal area (Decety et al., 1997; Grezes et al., 1998). The higher level of synchronization revealed under the condition for replica may be due to an additional recruitment of a pool of neurons, which would allow the visuomotor transformation to occur. Second, the spatial transformation (Anquetil \& Jeannerod, 2007) reflects a mechanism in which the observer has to transpose the body of the person she/he observed from an egocentric perspective at her/his own body. This body transposition, which is probably not necessary under the observation condition for recognition, may have a cost that can be expressed by an increase in synchronization under the observation condition for replica. However, as pointed out by Anquetil and Jeannerod (2007), the neural basis related to the perspective change from the observed person to the observer is still unknown and needs to be investigated.

The greater increase in synchronization revealed in upper alpha band under observation for replica compared to observation for recognition is also compatible with the behavioral results and the informal talks of the musically nai ve subjects. Musically nai" ve subjects made more mistakes under the observation for replica than under the observation for recognition. These also reported having experienced more memorization effort, more energy, and more attention when they observed a finger move- ment in order to replicate it at a later stage.

In the theta band, the relationship between synchronization values under observation for replica and observation for recognition is reversed compared to that obtained in the $10-13 \mathrm{~Hz}$ frequency band. In upper alpha band, a greater synchronization value under observation for replica was revealed, whereas, in theta band, the changes in synchronization across the two conditions were opposite in sign: the synchronization value was positive under observation for recognition; the synchronization value was negative and near zero under the observation for replica. These results are consistent with the findings of the ERD/ERS (Event-Related Desynchronization/Synchronization) literature related to memory tasks, which have shown that theta and al- 
pha react in different and antagonistic manners during the presentation of visual stimuli (Doppelmayr, Klimesch, Pachinger, \& Ripper, 1998; Klimesch, 1996, 1999; Klimesch, Schimke, \& Schwaiger, 1994; Klimesch, Doppelmayr, Pachinger, \& Ripper, 1997b; Klimesch et al., 1997a). These stimuli were, in fact, verbal materials such as letters, numbers, or words, and subjects were invited to provide a semantic judgment (Klimesch et al., 1997b) or/and to perform an episodic memory task (Klimesch, Doppelmayr, Pachinger, \& Russegger, 1997c). In the present study, where movements were presented, covariations display quite different patterns compared to those observed by Klimesch et al. This may be due to the use of different kinds of stimuli; movement sequences $v s$ verbal materials; and/or the use of different kinds of indicator; SL in the present study $v s$ ERD/ERS in studies conducted by Klimesch's research group. These different covariations also add weight to the idea that alpha and theta activities are produced by different mechanisms (Andersen \& Anderson, 1968; Klimesch, 1996, 1999; Steriade, Gloor, Llinas, Lopes da Silva, \& Mesulam, 1990). Cortical oscillations in alpha band translate activity stemming from the thalamus and induced to the cortex via thalamo-cortical pathways, whereas oscillations in theta band reflect activity emanating from the hippocampus and induced to the cortex via hippocampal cortical pathways (Andersen \& Anderson, 1968; Klimesch, 1996, 1999; Steriade et al., 1990).

\section{Observation for Replica and Recognition Among Professional Pianists}

In accordance with our second hypothesis, data tend to provide evidence for an EEG equivalence between the two observation conditions among professional pianists. Interpretation of this result has been made with great care since a lack of significant difference between two experimental conditions does not necessarily imply equality.

The lack of synchronization difference between the observation conditions for replica and recognition among the professional pianists may be explained by the reduced cortical network involved when these pianists watch an action which must be replicated in the near future. These individuals have acquired a high degree of musical expertise through an extensive and daily practice over, at least, a 10-year period. This musical training requires skills such as processing complex visuomotor transformations (Palmer, 1997), and learning by listening and observation in order to reproduce the teacher's actions (Haslinger et al., 2005). Under the observation condition for replica, we can thus conjecture that the recruitment of additional neuronal resources is not necessary to allow the visuomotor transformations to take place, since the pianists of the present study are used to treating visuomotor transformations from their earliest years. In other words, it can be supposed that pianists treat these transformations quasi-automatically or even effortlessly, and that the cost for this processing is negligible compared to musically nai ve subjects. In the first part of the discussion related to musically nai"ve subjects, we suggested that the synchronization difference between the two observation conditions was due to the cost gen- erated by an extra recruitment of a pool of neurons needed for the visuomotor transformation. Since this cost is negligible among the pianist population, such a difference disappears.

EEG equivalence detected between the two observation conditions in the professional pianists do not concur with their behavioral results and informal reports. The best scores in the task were obtained under observation for recognition, and professional pianists and these declared, as did the musically nai" ve subjects, that they perceived the replica condition to be more difficult than the recognition condition. This mismatch is difficult to explain.

Observation for Replica Among Musically Nai ve Subjects and Professional Pianists

The findings from this study also fit our third hypothesis. Functional coupling during observation for replica is greater in musically nai" ve subjects than in professional pianists. This result is consistent with the behavioral results. Musically nar ve subjects committed more mistakes than professional pianists as they per-formed the sequential finger movements. This result is also deemed logical when examining the aforementioned findings of this study. As suggested by the authors, the greater coupling observed in musically nai" ve subjects is due to the mechanisms related to visuomotor/spatial transformation, which differs ac- cording to the musical expertise of the individuals. To perform visuomotor/spatial transformation, physically nai" ve subjects need to recruit sets of neurons more extensively than profes- sional pianists. These points were reviewed thoroughly and ear- lier in the discussion.

The next point that needs to be addressed is related to the nature of the task of the present study. The task was a sequential finger-to-thumb opposition movement with the right hand in a supine position. It was not a piano hand movement, which is characterized by up-and-down movements of the fingers striking keys on a piano's keyboard and with the hands in a prone position. While the sequential finger-to-thumb opposition movements were unfamiliar for all subjects, the EEG results suggest that, contrary to musically nai" ve subjects, professional pianists were able to process the visuomotor transformation with no cost or, at least, with a reduced processing treatment. This

difference can be explained by the fact that the sequential

finger-to-thumb opposition movements may have been perceived by the profes- sional pianists as a closed piano-related task and that the task may have appeared more meaningful to them compared to the mu- sically nai ve subjects. If the task

had displayed more remote characteristics of musical hand movements, the results would have been probably different.

This hypothesis has yet to be tested. Finally, the difference observed between the pianists and the musically nai"ve subjects corroborates recent studies that com- pared cortical activations during observation sessions in expert and inexpert individuals using the fMRI technique (Calvo-Me- rino et al.,

2005, 2006; Haslinger et al., 2005). For example, Calvo-

Merino et al. (2005) reported stronger bilateral activations in

premotor cortex, intraparietal sulcus, right superior parietal lobe, and left posterior superior temporal sulcus in expert dancers when observing passively familiar dance movements that they were used to performing daily, in comparison to movements they had never performed. In the field of music, Haslinger et al. (2005) found a greater involvement of the fronto-parieto-temporal network in pianists compared to inexperienced pianists as they passively observed piano-playing movements. They also demonstrated that primary and second auditory areas were bilaterally activated only among pianists during the viewing of soundless piano-playing movements. While there is evidence for a difference between experts and novices in the literature, comparison with research that has not used the EEG technique should be made cautiously. Activation of a given area, expressed by blood oxygen level dependent (BOLD) signal, does not reflect similar aspects of cortical activity as does interregional functional coupling. 
Conclusion

The use of the non-linear technique (Stam \& van Dijk, 2002; Montez et al., 2006) provided an opportunity to analyze in detail several mechanisms underlying observation. The results indicated that the nature of instructions provided prior observation and the level of expertise of the observer led to different cerebral rhythmic activities within central and neighboring areas.

\section{REFERENCES}

Andersen, P., \& Anderson, S. A. (1968). Physiological basis of the alpha rhythm. New York: Century Crofts.

Andres, F. G., Mima, T., Schulman, A. E., Dichgans, J., Hallett, M., \& Gerloff, C. (1999). Functional coupling of human cortical sensorimotor areas during bimanual skill acquisition. Brain, 122, 855-870.

Anquetil, T., \& Jeannerod, M. (2007). Simulated actions in the first and in the third person perspectives share common representation. Brain Research, 1130, 125-129.

Babiloni, C., Babiloni, F., Carducci, F., Cincotti, F., Del Percio, C., Vito Moretti, D., \& Rossini, P. M. (2002). Quantitative EEG: Modeling time, space, and phase of brain oscillatory activity. In R. C. Reisin, M. R. Nuwer, M. Hallett, \& C. Medina (Eds.), Advances in clinical neurophysiology (pp. 284-288). Amsterdam: Elsevier Science.

Babiloni, C., Del Percio, C., Rossini, P. M., Marzano, N., Iacoboni, M., Infarinato, F., et al. (2009). Judgement of actions in experts: A highresolution EEG study in elite athletes. NeuroImage, 45, 512-521.

Besthorn, C., Sattel, H., Geiger-Kabisch, C., Zerfass, R., \& Forstl, H. (1995). Parameters of EEG dimensional complexity in Alzheimer's disease. Electroencephalography and Clinical Neurophysiology, 95, 8489.

Bliss, T. V. P., \& Collingridge, G. L. (1993). A synaptic model of memory: Long-term potentiation in the hippocampus. Nature, 361, 31-39.

Bonda, E., Petrides, M., Ostry, D., \& Evans, A. (1996). Specific involvement of human parietal systems and the amygdale in the perception of biological motion. Journal of Neuroscience, 16, 3737-3744.

Calmels, C., Hars, M., Holmes, P., Jarry, G., \& Stam, C. J. (2008). Nonlinear EEG synchronization during observation and execution of simple and complex sequential finger movements. Experimental Brain Research, 190,389-400.

Calmels, C., Holmes, P., Jarry, G., Hars, M., Lopez, E., Paillard, A., \& Stam, C. J. (2006). Variability of EEG synchronization prior to and during observation and execution of a sequential finger movement. Human Brain Mapping, 27, 251-266.

Calvo-Merino, B., Glaser, D. E., Grezes, J., Passingham, R. E., \& Haggard, P. (2005). Action observation and acquired motor skills: An fMRI study with expert dancers. Cerebral Cortex, 15, 1243-1249.

Calvo-Merino, B., Grezes, J., Glaser, D. E., Passingham, R. E., \& Haggard, P. (2006). Seeing or doing? Influence of visual and motor familiarity in action observation. Current Biology, 16, 1905-1910.

Chainay, H., Krainik, A., Tanguy, M. L., Gerardin, E., Le Bihan, D., \& Lehé ricy, S. (2004). Foot, face and hand representation in the human supplementary motor area. NeuroReport, 15, 765-769.

Decety, J., \& Grezes, J. (1999). Neural mechanisms subserving the perception of human actions. Trends in Cognitive Sciences, 3, 172-178.

Decety, J., Grezes, J., Costes, N., Perani, D., Jeannerod, M., Procyk, E., et al. (1997). Brain activity during observation of actions. Influence of action content and subject's strategy. Brain, 120, 1763-1777.

Derambure, P., Defebvre, L., Bourriez, J. L., Cassim, F., \& Guieu, J. D. (1999). Dé synchronisation et synchronisation lié es à l'é vé nement. Etude de la ré activité des rythmes é lectrocorticaux en relation avec la planification et l'exé cution du mouvement volontaire [Event-related desynchronization and synchronization. Reactivity of cortical elec- troencephalographic rhythms related to planning and performance of voluntary movement]. Neurophysiologie Clinique, 29,53-70.

Doppelmayr, M., Klimesch, W., Pachinger, T., \& Ripper, B. (1998). Individual differences in brain dynamics: Important implications for the calculation of event-related band power measures. Biological Cybernetics, 79, 49-57.

Ericsson, K. A., Krampe, R. T., \& Tesch-Romer, C. (1993). The role of deliberate practice in the acquisition of expert performance. Psychological Review, 100, 363-406.

Gerloff, C., Richard, J., Hadley, J., Schulman, A. E., Honda, M., \& Hallett, M. (1998). Functional coupling and regional activation of human cortical motor areas during simple, internally paced and externally paced finger movements. Brain, 121, 1513-1531.
Grafton, S. T., Arbib, M. A., Fadiga, L., \& Rizzolatti, G. (1996). Localization of grasp representations in humans by positron emission tomography. Experimental Brain Research, 112, 103-111.

Grezes, J., Costes, N., \& Decety, J. (1998). Top-down effect of strategy on the perception of human biological motion: A PET investigation. Cognitive Neuropsychology, 15,553-582.

Grezes, J., \& Decety, J. (2001). Functional anatomy of execution, mental simulation, observation and verb generation of actions: A meta-analysis. Human Brain Mapping, 12, 1-19.

Haslinger, B., Erhard, P., Altenmuller, E., Hennenlotter, A., Schwaiger, M., Grafin von Einsiedel, H., et al. (2004). Reduced recruitment of motor association areas during bimanual coordination in concert pianists. Human Brain Mapping, 22, 206-215.

Haslinger, B., Erhard, P., Altenmuller, E., Schroeder, U., Boecker, H., \& Ceballos-Baumann, A. O. (2005). Transmodal sensorimotor networks during action observation in professional pianists. Journal of CognitiveNeuroscience, 17, 282-293.

Holz, E. M., Doppelmayr, M., Klimesch, W., \& Sauseng, P. (2008). EEG correlates of action observation in humans. Brain Topography, 21, 9399.

Iacoboni, M., Woods, R. P., Brass, M., Bekkering, H., Mazziotta, J. C., \& Rizzolatti, G. (1999). Cortical mechanisms of human imitation. Science, 286, 2526-2528.

Jackson, P. L., Meltzoff, A. N., \& Decety, J. (2006). Neural circuits involved in imitation and perspective-taking. NeuroImage, 31, 429439

Jancke, L., Shah, N. J., \& Peters, M. (2000). Cortical activations in primary and sensory motor areas for complex bimanual movements in professional pianists. Cognitive Brain Research, 10, $177-183$.

Jasper, H. H. (1958). Report of the Committee on Methods of Clinical Examination in Electroencephalography. Electroencephalography and ClinicalNeurophysiology, 10,370-375.

Jeannerod, M. (2001). Neural simulation of action: A unifying mechanism for motor cognition. NeuroImage, 14, S103-S109.

Jeannerod, M. (2006). Motor cognition: What actions tell the self. Oxford: Oxford University Press.

Jeannerod, M., Arbib, M. A., Rizzolatti, G., \& Sakata, H. (1995). Grasping objects: The cortica mechanisms of visuomotor transformation. Trends in Neuroscience, 18, 314-320.

Klimesch, W. (1996). Memory processes, brain oscillations and EEG synchronization. International Journal of Psychophysiology, 24, 61100 .

Klimesch, W. (1999). EEG alpha and theta oscillations reflect cognitive and memory performance: A review and analysis. Brain Research Reviews, 29, 169-195.

Klimesch, W., Doppelmayr, M., Pachinger, T., \& Ripper, B. (1997b). Brain oscillations and human memory performance: EEG correlates in the upper alpha and theta bands. Neuroscience Letters, 238, 9-12.

Klimesch, W., Doppelmayr, M., Pachinger, T., \& Russegger, H. (1997c). Event-related desynchronization in the alpha band and the processing of semantic information. Cognitive Brain Research, 6, 83-94.

Klimesch, W., Doppelmayr, M., Schimke, H., \& Ripper, B. (1997a). Theta synchronization and alpha desynchronization in a memory task. Psychophysiology, 34, 169-176.

Klimesch, W., Schimke, H., \& Schwaiger, J. (1994). Episodic and semantic memory: An analysis in the EEG-theta and alpha band. Electroencephalography and Clinical Neurophysiology, 91, 428-441.

Koeneke, S., Lutz, K., Wustenberg, T., \& Jancke, L. (2004). Long-term training affects cerebellar processing in skilled keyboard players. $\mathrm{Ne}$ uroReport, 15, 1279-1282.

Krings, T., Topper, R., Foltys, H., Erberich, S., Sparing, R., Willmes, K., \& Thron, A. (2000). Cortical activation patterns during complex motor tasks in piano players and control subjects. A functional magnetic resonance imaging study. Neuroscience Letters, 278, 189-193. 
Lepage, J. F., \& Thé oret, H. (2006). EEG evidence for the presence of an action observation-execution matching system in children. European JournalofNeuroscience, 23, 2505-2510.

Maeda, F., Kleiner-Fisman, G., \& Pascual-Leone, A. (2002). Motor facilitation while observing hand actions: Specificity of the effect and role of observer's orientation. Journal of Neurophysiology, 87, 13291335.

Magill, R. A. (2004). Motor learning and control. Concepts and applications. New York: McGraw-Hill Companies.

Makuuchi, M. (2005). Is Broca's area crucial for imitation? Cerebral Cortex, 15, 563-570.

Manganotti, P., Gerloff, C., Toro, C., Katsuda, H., Sadato, N., Zhuang, P., et al. (1998). Task-related coherence and task-related spectral power changes during sequential finger movements. Electroencephalography and Clinical Neurophysiology, 109, 50-62.

Matelli, M., \& Luppino, G. (2000). Parietofrontal circuits: Parallel channels for sensory-motor integrations. Advances in Neurology, 84, $51-61$.

Meister, I., Krings, T., Foltys, H., Boroojerdi, B., Muller, M., Topper, R., \& Thron, A. (2005). Effects of long-term practice and task complexity in musicians and nonmusicians performing simple and complex motor tasks: Implications for cortical motor organization. Human Brain Mapping, 25, 345-352.

Montez, T., Linkenkaer-Hansen, K., van Dijk, B. W., \& Stam, C. J. (2006). Synchronization likelihood with explicit time-frequency priors. NeuroImage, $33,1117-1125$.

Muthukumaraswamy, S. D., Johnson, B. W., \& McNair, N. A. (2004). $\mathrm{Mu}$ rhythm modulation during observation of an object-directed grasp. Cognitive Brain Research, 19, 195-201.

Oldfield, R. C. (1971). The assessment and analysis of handedness: The Edinburgh Inventory. Neuropsychologia, 9, 97-113.

Palmer, C. (1997). Music performance. Annual Review of Psychology, 48, $115-138$.

Pijn, J. P. M., van Neerven, J., Noest, A., \& Lopes da Silva, F. H. (1991). Chaos or noise in EEG signals: Dependence on state and brain site. Electroencephalography and Clinical Neurophysiology, 79, 371381.

Pineda, J. A. (2005). The functional significance of mu rhythms: Translating "seeing" and "hearing" into "doing". Brain Research Reviews, $50,57-68$

Rizzolatti, G., \& Craighero, L. (2004). The mirror-neuron system. Annual Review of Neuroscience, 27, 169-192.

Rizzolatti, G., Craighero, L., \& Fadiga, L. (2002). The mirror system in human. In M. I. Stamenov \& V. Gallese (Eds.), Mirror neurons and the evolution of brain and language (pp. 37-63). Philadelphia: John Benjamins Publishing Company.

Rizzolatti, G., Luppino, G., \& Matelli, M. (1998). The organization of the cortical motor system: New concepts. Electroencephalography and Cinical Neurophysiology, 106, 283-296.

\section{APPENDIX 1}

Epoch length is an important parameter to take into consideration in non linear analyses. Epochs should be long enough for reliable estimates of non linear measures but not too long, otherwise the requirement of stationarity is not fulfilled (Stam, Jelles, Achtereekte, Rombouts, Slaets, \& Keunen, 1995). In the literature, employing short epoch length to compute non linear analyses is not frequent (Besthorn, Sattel, Geiger-Kabisch, Zerfass, \& Forstl, 1995; Pijn, van Neerven, Noest, \& Lopes da Silva, 1991; Stam et al., 1995; Woyshville \& Calabrese, 1994). However, it has been proven that employing short EEG data segments allows reliable results.

For example, Besthorn et al. (1995) investigated the influence of epoch length on the estimation of dimensional complexity in normal healthy subjects. Four epoch lengths of 512, 1,024, 2,048, and 4,096 points were considered (sampling frequency 5200 $\mathrm{Hz}$ ). Besthorn et al. (1995) found that, irrespective of the epoch length, values of dimensional complexity were robust from 512 to 1,046 points (i.e., $2.5 \mathrm{~s}$ to $20 \mathrm{~s}$ ).
Sauseng, P., Klimesch, W., Gruber, W., Doppelmayr, M., Stadler, W., \& Schabus, M. (2002). The interplay between theta and alpha oscillations in the human electroencephalogram reflects the transfer of information between memory systems. Neuroscience Letters, 324, 121124

Sauseng, P., Klimesch, W., Schabus, M., \& Doppelmayr, M. (2005). Fronto-parietal EEG coherence in theta and upper alpha reflect central executive functions of working memory. International Journal of Psychophysiology, 57,97-103.

Semlitsch, H., Anderer, P., Schuster, P., \& Presslich, O. (1986). A solution for reliable and valid reduction of ocular artifacts, applied to the P300 ERP. Psychophysiology, 23, 695-703.

Shiffrin, R. M., \& Geisler, W. (1973). Visual recognition in a theory of information processing. In R. L. Solso (Ed.), Contemporary Issues in Cognitive Psychology: The Loyola Symposium (pp. 53-101). Washington: Winston.

Sirigu, A., Duhamel, J. R., Cohen, L., Pillon, B., Dubois, B., \& Agid, Y. (1996). The mental representation of hand movements after parietal cortex damage. Science, 273, 1564-1568.

Stam, C. J., de Haan, W., Daffertshofer, A., Jones, B. F., Manshanden, I., van Cappellen van Walsum, A. M., et al. (2009). Graph theoretical analysis of magnetoencephalographic functional connectivity in Alzheimer's disease. Brain, 132, 213-224.

Stam, C. J., Jelles, B., Achtereekte, H. A. M., Rombouts, S. A. R. B., Slaets, J. P. J., \& Keunen, R. W. M. (1995). Investigation of EEG non linearity in dementia and Parkinson's disease. Electroencephalography and Clinical Neurophysiology, 95,309-317.

Stam, C. J., \& van Dijk, B. W. (2002). Synchronization likelihood: An unbiased measure of generalized synchronization in multivariate data sets. Physica D, 163, 236-251.

Stark, A., \& Zohary, E. (2008). Parietal mapping of visuomotor transformations during human tool grasping. Cerebral Cortex, 18, 23582368.

Steriade, M., Gloor, P., Llinas, R. R., Lopes da Silva, F. H., \& Mesulam, M. M. (1990). Basic mechanisms of cerebral rhythmic activities. Electroencephalography and Clinical Neurophysiology, 76, 481-508.

Suchan, B., Melde, C., Herzog, H., Homberg, V., \& Seitz, R. J. (2008). Activation differences in observation of hand movements for imitation or velocity judgement. Behavioural Brain Research, 188, 78-83.

Woyshville, M. J., \& Calabrese, J. R. (1994). Quantification of occipital EEG changes in Alzheimer's disease utilizing a new metric: The fractal dimension. Biological Psychiatry, 35, 381-387.

Zentgraf, K., Stark, R., Reiser, M., Kunzell, S., Schienle, A., Kirsch, P., et al. (2005). Differential activation of pre-SMA and SMA proper during action observation: Effects of instructions. NeuroImage, 26, 662-672.

(Received June 2, 2009; Accepted September 5, 2009)

Similarly, Stam et al. (1995) examined the influence of epoch length on the estimations of correlation dimension (D2), Lyapunov exponent (L1), and Kolmogorov entropy (K2) based on spatial delay embedding in healthy subjects. Five epoch lengths of $100,200,300,400$, and 500 points were considered (sampling frequency $5200 \mathrm{~Hz}$ ). Stam et al. (1995) demonstrated a significant increase in all measures when epoch length was increased from 200 to 300 (i.e., $1 \mathrm{~s}$ to $1.5 \mathrm{~s}$ ) and from 300 to 400 points (i.e., $1.5 \mathrm{~s}$ to $2 \mathrm{~s}$ ). Further increase of the sample size to 512 displayed no significant increase in any of the measures.

As far as SL is concerned, one of the issues in developing this measure was to have a general, unbiased measure of synchronization that could track rapid changes in levels of synchronization. The high temporal resolution of this measure has been proven for simulated data and real data in Stam and van Dijk's paper (2002). In particular, it should be noted that SL displayed multiple rapid changes of gamma band synchronization in healthy subjects. The fact that most studies using SL measure 
employed longer epochs compared to that used in the present study should not be seen as an intrinsic limitation of this technique. What is required is an epoch length that is long enough to incorporate the $\mathrm{lag}^{\mathrm{n}}$ embedding dimension. Thus, if the values of the lag and the embedding dimension are small, short epoch can be analyzed. For instance, if the values were 1 sample for the lag, 10 for the embedding dimension, and 10 for the Theiler correction, epochs of 50-100 samples can be analyzed.

To extend this work, a simulation has been undertaken to demonstrate that SL can be used on short epoch lengths. In the present case, the epoch length was 100 samples, and there were 21 channels. Parameters for the SL computation were: 1 sample for the lag; 5 for the embedding dimension; 5 for the Theiler correction $\left(\mathrm{w}_{1}\right) ; 0.05$ for Pref; and 1 for the speed. The epoch, which has been examined, was filled with uncorrelated white noise. In the middle part, namely, from sample 30 to sample 80 , correlation has been induced by copying channel 1 to all the other channels (see Figure A1).

SL was then computed and the results were displayed in Figure A2. From sample 30 to sample 80, a great increase of synchronization was detected. This simulation shows that: (i) SL can be used with short epoch lengths, and (ii) even within a very short epoch length, SL can still pick up reliably very brief fluctuations of synchronization.

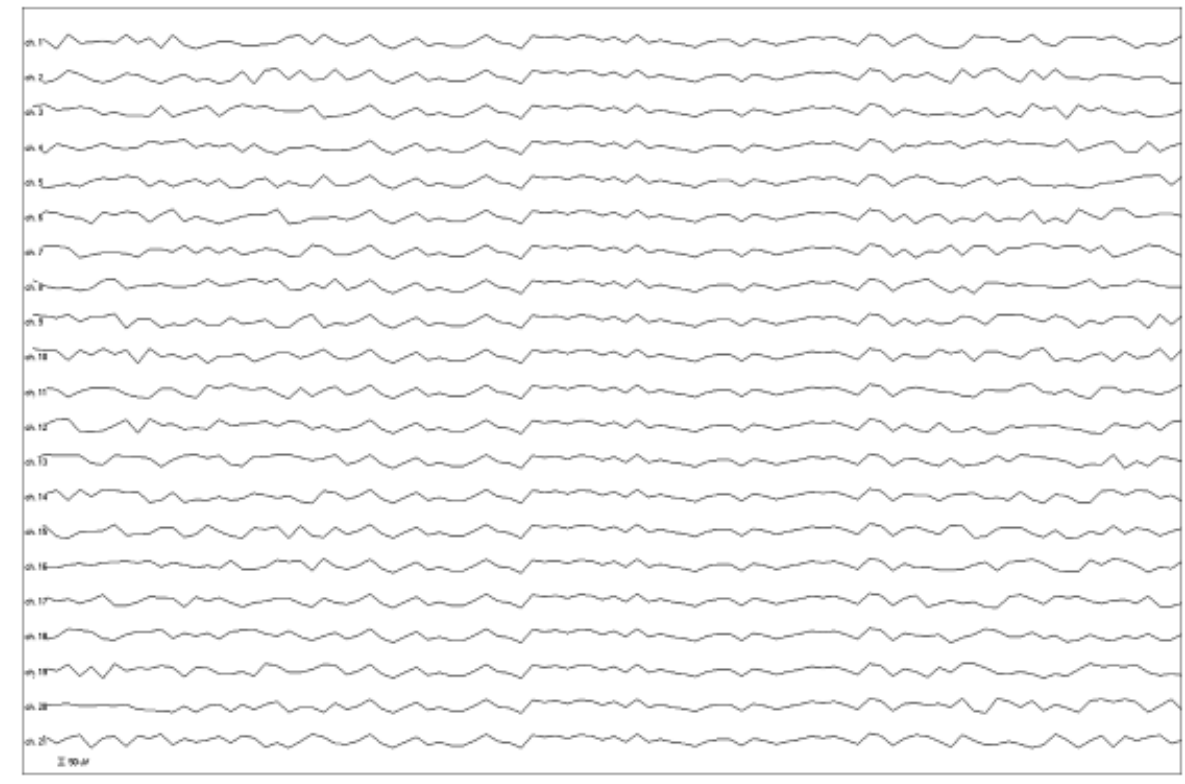

Figure A1. Experimental data used for the simulation.

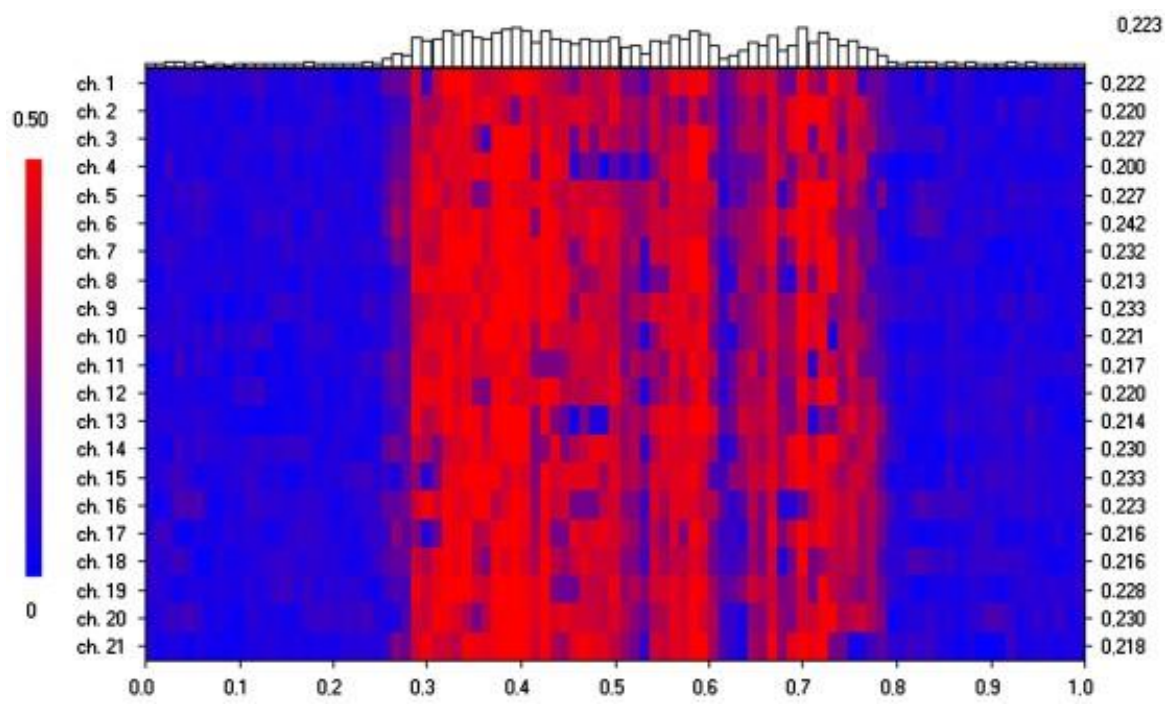

Figure A2. The SL within a 100 sample-epoch length. The abscissa represents time (in seconds), the ordinate indicates the EEG channels. The value of the SL for each channel and each time point is indicated through a color scale; red shades correspond to higher levels of synchronization whereas blue shades represent lower levels of synchronization. The numbers on the right scale indicate the average synchronization values for each of the channels. The curve at the top of each diagram reflects the time course of the SL averaged over all channels. 